\title{
CHANGING ATTITUDES WITH A MOOC ON DEMENTIA
}

\author{
David Robertshaw [d.robertshaw@derby.ac.uk],YasubiroKotera [Y.Kotera@derby.ac.uk],University of \\ Derby, Kedleston Road, Derby, DE22 1GB, United Kingdom
}

\begin{abstract}
Introduction

Dementia is one of the most significant issues of our time and there are varying prevailing attitudes towards dementia, including negative stigma and perception. Massive open online courses (MOOCs) are a widely available online learning resource accessed for free which may present an opportunity to address prevailing attitudes.
\end{abstract}

\section{Methodology}

We conducted a questionnaire before and after a six-week MOOC where participants learned about dementia. We collected data using a survey instrument and analysed them with statistical testing.

\section{Results and findings}

Although there was no statistically significant change between pre- and post-MOOC questionnaires, the change was observed in some questions and for particular groups.

\section{Conclusion and recommendations}

Our findings indicate this MOOC has a greater effect on changing the attitudes of non-healthcare workers, older people and those living in the United Kingdom. We recommend further analysis of MOOC as a change intervention and consideration of their application in other disciplines.

Key words: MOOC; Dementia; Social; Attitudes; Attitudinal Change.

\section{Introduction}

Dementia, one of the most significant issues of our time, is a complicated syndrome of diseases affecting brain structure and function. This leads to loss of cognitive function and memory with a decline in social and emotional capacity (Kitwood, 1997; De Bellis \& Williams, 2008; World Health Organization and Alzheimer's Disease International, 2012). A progressive disease, dementia reduces the ability to perform daily activities leading to increased dependence on carers and family members (Alzheimer's Society, 2015). Dementia is one of the most feared diseases, above cancer, heart disease, diabetes and stroke, which may be due to a lack of education or awareness about dementia, stigma or stereotypes (Harris Interactive, 2011). There are also challenging attitudes towards dementia among professional care staff: care home staff have been shown to perceive people with dementia as having little control over their lives, being anxious and unpredictable (Brodaty et al., 2003). Student nurses have been shown to have positive attitudes towards dementia, associated with good knowledge; increasing experience is known to improve positive attitudes (Scerri \& Scerri, 2013). Fifty-three percent of people living with dementia feel anxious or depressed (Kane \& Terry, 2015), and less than 50\% of people living with dementia are formally diagnosed (Prince, Bryce, \& Ferri, 2011). National dementia strategies in Australia, England, France, and Wales recognise the association between lack of knowledge 
and stigma in dementia and aim to increase awareness among their populations as a result (Pot, Petrea, \& Meerveld, 2013). These strategies and plans generally focus on advocacy, awareness raising, and capacity building: actions, which should be specific to their own context (World Health Organisation, 2012). Implementation of plans like these requires the application of change methodologies and interventions. One example of these methodologies is Lewin's model of unfreezing, changing and refreezing: recognising these stages allows analysis of the situation, implementing a change and then establishing a stable state (Kaminski, 2011).

There have been a number of change interventions aimed at dementia. Elvish et al. (2014) implemented a six-hour intervention entitled "Getting to Know Me" which had a significant impact on staff knowledge and confidence in relation to dementia (George, Stuckey, \& Whitehead, 2013) designed a creative group-based storytelling program involving people living with dementia and medical students and showed that participation improved their attitudes towards people with dementia. Grigsby et al. (2017) used an audio-visual novella to improve knowledge and attitudes about dementia and Tan etal. (2017) reported that team-based inter-professional competency training can enhance competency in dementia screening and management among medical, nursing, pharmacy, and social work practitioners. Low et al. (2015) undertook a systematic review of change interventions to enhance staff practice in nursing homes and showed that change is possible but complex to implement and maintain. A large-scale change intervention aimed at dementia has been the Dementia Friends initiative. Although there have been no published national evaluations of Dementia Friends, Mitchell et al. (2016) undertook a small scale evaluation with medical students and showed an increase in knowledge and confidence as a result of the programme. There are over one million Dementia Friends in the United Kingdom, exceeding the estimated number of people with dementia, approximately 850,000 (Alzheimer's Society, 2015), however larger scale easier-to access initiatives may require consideration.

One such area of developing practice for social change interventions is in massive open online courses (MOOCs) (Robertshaw \& Cross, 2016). MOOCs are very large open access online courses. They are open to anyone who wishes to study them, and openness also relates to the use of open-course platforms, curricula, information and assessment processes (Rodriguez, 2012). MOOCs can be used to characterise social experiences using participant information and contributions (Robertshaw \& Cross 2017; Robertshaw \& Cross, 2018; McInerny et al., 2018; Goldberg et al., 2015; Mehta et al., 2013; Rawlings et al., 2017; Annear et al., 2016). MOOCs are a source of big data, which can be analysed to bring new insights or perspectives (O'Reilly \& Veeramachaneni, 2014), but they also present a unique opportunity for dementia by allowing wide open free access to high-quality learning materials on dementia.

Consisting of six units of learning, the University of Derby MOOC entitled "Bridging the Dementia Divide" aimed to support the WHO's change agenda by encouraging societal participation in education, research and partnership working (World Health Organisation, 2012). The six units were on:

1. Introduction to dementia

2. Communication and compassion

3. Independence, control and quality of life

4. Dementia as a global health priority

5. Integrating care

6. End of life care 
The MOOC was designed to unfreeze and change attitudes of dementia through social learning opportunities, storytelling and inspiring voices with the joining of many threads including knowledge, collaborative skills, the person-centred approach, environmental factors, ethical competence and practice leadership (Forman \& Pond, 2015). This MOOC has been reported to have high levels of engagement and retention and has encouraged some learners to re-evaluate their perspectives and attitudes (Petronzi \& Hadi, 2016). The course was designed, directed and taught by a small number of Registered Nurses who were supported by lay-discussion board facilitators. The course was built by learning technologists part of an innovation unit focused on innovative pedagogies.

This study aims to ascertain the impact of a massive open online course on dementia delivered in 2015, 2016 and 2017, on attitudes towards dementia. The course included six units of learning over six weeks and was designed to be open and accessible by all. The course saw dementia in a positive and constructive light, rather than focusing on the negative aspects of dementia. Attitudes are defined as a "mental or neural readiness state derived through experience, with a directive or dynamic effect on a person's responses to situations" that change how individuals feel and the actions they take because of experience (Allport, 1935). Attitudes are affected by feelings, behaviour, and cognition and are complex, and may change over time so that people see something in a different way (Myers, 2013). However, we are not aware of any studies which explore how attitudes towards dementia are characterised or change over time.

\section{Aims and hypotheses}

This study aimed to examine if a MOOC on dementia can be used to make demonstrable changes to attitudes towards dementia. Four hypotheses were developed to test:

- Hypothesis 1: There would be a significant median difference between pre- and postMOOC assessments for the attitudes towards dementia.

- Hypothesis 2: There would be a significant median difference in people's attitudes towards someone who has been newly diagnosed with dementia and who has been living with dementia for a long time.

- Hypothesis 3: The change in the attitudes towards dementia between pre- and postMOOC would be different between healthcare and non-healthcare workers

- Hypothesis 4: The change in the attitudes towards dementia between pre- and postMOOC and demographics would be related to each other.

\section{Methodology}

This study utilised the Northern Ireland Life and Times survey on dementia: an un-validated survey examining attitudes towards dementia and capacity for independent living in Northern Ireland (Dowds et al., 2010). The tool has been used twice to assess attitudes towards dementia in 2010 and 2014 (Devine, 2015). Permission to use this survey was received from its designers and this survey was used to assess the attitudes of participants before and after studying the MOOC, evaluating the course as an intervention. Ethical approval was gained from the University of Derby's Ethics Committee and conformed to the British Psychological Society's requirements for internet-mediated research (British Psychological Society, 2017).

\section{Participants}

Participants were invited via a web page in the MOOC to complete in the survey. The MOOC ran during 2015, 2016 and 2017 and a total of 8,238 people enrolled. Participation in this survey was optional and learners could continue the course without completing the survey. Using opportunity sampling, a total of 956 participants agreed to participate of which 107 (16 males and 
91 females; Age 41-50 years $=28,51-60$ years $=26,21-30$ years $=20,31-40$ years $=19,61-70$ years $=10,16-20$ and $71-80$ years $=2$ respectively) completed the questionnaire both at pre- and post-MOOC stages. Seventy-four percent were British $(n=79)$, and the remaining $28 \%$ included nine Oceanians, seven North-Americans, six other Europeans, three Africans, two Asians, and one South-American. Sixty-one percent were healthcare workers $(n=65) ; 37 \%$ included managers, students, and researchers with no area specified, and retirees $(n=40)$; and $2 \%$ did not answer $(n=2)$.

\section{Questionnaire}

Participants were asked demographic questions, and then asked to agree or disagree on a 5-item Likert scale $(1$ - strongly disagree to 5 - strongly agree $)$ with the statements in Table 1.

Table 1: NILT Questions

Question 15. There comes a time when all you can do for someone with dementia is to keep them clean, healthy and safe.

Question 17. Other people take over making decisions for people with dementia far too much.

Question 19. Once they have dementia the person you knew eventually disappears.

Question 20. As soon as someone is diagnosed with dementia they are not treated like a thinking human being any more.

Question 22. For people with really bad dementia I don't think life is worth living.

Question 23. People with dementia are like children and need cared for as you would a child.

Question 24. People with dementia should be involved in activities in the community

Question 25. It is better for people with dementia and their families if they are cared for in a residential unit or a nursing home.

Question 26. There is little or no benefit to be gained from telling someone they have dementia.

Question 27. People who have just been diagnosed with dementia are unable to make decisions about their own care.

Question 28. There is no point in trying to talk to people with dementia as they won't be able to understand.

Question 30. Should someone newly diagnosed with dementia...Continue to live alone.

Question 31. Should someone newly diagnosed with dementia...Continue to manage their own medication.

Question 32. Should someone newly diagnosed with dementia...Continue to drive.

Question 33. Should someone newly diagnosed with dementia... Have an electronic device fitted so they can be located if they wander.

Question 36. Should someone who has been living with dementia for a long time...Continue to live alone.

Question 37. Should someone who has been living with dementia for a long time...Continue to manage their own medication.

Question 38. Should someone who has been living with dementia for a long time...Continue to drive.

Question 39. Should someone who has been living with dementia for a long time... Have an electronic device fitted so they can be located if they wander.

\section{Data collection and analysis}

Data were gathered in Qualtrics and then exported to Excel 2013 and SPSS 24.0 for analysis, and participants were matched in both surveys using the same unique identifying numbers. The scores for Questions 24, 30, 31, 32, 36, 37, and 38 were reversed in order to align the direction of the responses: a lower score indicates a positive attitude towards dementia. The data were then 
screened for outliers and normality. As the data were not normally distributed assessed by the Shapiro-Wilk test $(p<.05)$, and data-transformation did not satisfy the assumption of normality, nonparametric tests were used. First, Wilcoxon Signed-Rank test was conducted in order to compare their attitudes towards dementia between pre- and post-MOOC (H1), and between their attitudes towards someone newly diagnosed and someone living with dementia for a long time (H2). Second, the Kruskal-Wallis $\mathrm{H}$ test was used to examine whether the change in the attitudes towards dementia made through the MOOC would be different between healthcare and nonhealthcare workers (H3). Lastly, Kendall's tau-b correlation analysis was conducted exploring relationships between their demographic information and changes in the attitudes towards dementia (H4).

\section{Results}

Descriptive statistics for pre- and post-MOOC scores of all the questions and the total score are reported in Table 2. Six scores for Questions 17 and five scores for Question 36 at pre-MOOC, and eight scores for Questions 22 and 30 at Post-MOOC were identified as outliers using the outlier labelling rule (Hoaglin \& Iglewicz, 1987), thus were Winsorised (Tukey, 1962). The range of skewness value was 2.44 to -1.14 , and of kurtosis value was 9.30 to -1.18 . Cronbach's alpha for all the pre-MOOC scores was .77 , and post-MOOC scores were .93, demonstrating high internal consistency for answer scores.

Table 2: Descriptive statistics and comparisons for the attitudes towards dementia pre- and postMOOC scores $(n=107)$

\begin{tabular}{|c|c|c|c|c|c|c|c|c|}
\hline & \multicolumn{4}{|c|}{ Pre-MOOC } & \multicolumn{4}{|c|}{ Post-MOOC } \\
\hline & $\mathrm{M}$ & SD & Skewness & Kurtosis & $M$ & SD & Skewness & Kurtosis \\
\hline Q15 & $2.61^{*}$ & 1.32 & .33 & -1.18 & 2.24 & .93 & .35 & -.36 \\
\hline Q17 & $3.89^{* * *}$ & .59 & .02 & -.13 & 1.90 & .82 & 1.02 & 1.54 \\
\hline Q19 & $3.09^{* * *}$ & 1.08 & -.05 & -1.04 & 1.46 & .74 & 2.11 & 5.72 \\
\hline Q20 & $3.14^{* * *}$ & 1.09 & .02 & -1.05 & 1.36 & .64 & 2.44 & 9.30 \\
\hline Q22 & 2.25 & 1.07 & .60 & -.17 & 2.03 & .67 & -.02 & -.70 \\
\hline Q23 & 2.32 & 1.17 & .76 & -.33 & 2.43 & .92 & .63 & -.24 \\
\hline Q24 & 2.39 & .94 & .25 & -.17 & 2.65 & 1.19 & .33 & -.82 \\
\hline Q25 & 2.10 & .87 & .77 & .61 & $3.19^{* * *}$ & .99 & .03 & -.35 \\
\hline Q26 & 1.58 & .79 & 1.73 & 3.80 & $3.45^{* * *}$ & .91 & -.12 & -.46 \\
\hline Q27 & 1.39 & .67 & 2.42 & 8.58 & $3.60^{* * *}$ & .90 & -.14 & -.34 \\
\hline Q28 & 2.46 & .95 & .34 & .02 & $3.17^{* * *}$ & 1.26 & -.15 & -.93 \\
\hline Q30 & $3.00^{* * *}$ & .96 & -.02 & -.26 & 2.03 & .67 & -.02 & -.70 \\
\hline Q31 & $4.20^{* * *}$ & 1.04 & -.88 & -.46 & 2.43 & .92 & .63 & -.24 \\
\hline Q32 & $3.58^{* * *}$ & .88 & -.01 & -.69 & 2.68 & .92 & .70 & .23 \\
\hline Q33 & 2.56 & 1.16 & .55 & -.25 & 2.65 & 1.19 & .33 & -.82 \\
\hline Q36 & $4.10^{* * *}$ & .61 & -.06 & -.33 & 3.19 & .99 & .03 & -.35 \\
\hline Q37 & 3.20 & 1.18 & -0.21 & -.90 & 3.45 & .91 & -.12 & -.46 \\
\hline Q38 & 2.02 & 1.03 & 1.03 & .63 & $3.60^{* * *}$ & .90 & -.14 & -.34 \\
\hline Q39 & 1.51 & .62 & .80 & -.32 & $3.17^{* * *}$ & 1.26 & -.15 & -.93 \\
\hline$\alpha$ & \multicolumn{4}{|c|}{.78} & \multicolumn{4}{|c|}{.92} \\
\hline Total & 51.29 & 8.25 & .74 & .81 & 50.85 & 12.03 & .49 & .11 \\
\hline
\end{tabular}




\section{Wilcoxon signed-rank test}

Wilcoxon signed-ranked test was used in order to examine whether there was a median difference between pre-MOOC attitudes scores and post-MOOC attitudes scores (H1). There were significant decreases from pre-MOOC to post-MOOC in Questions 15, 17, 19, 20, 30, 31, 32, and 36, while significant increases in Questions 25, 26, 27, 28, 38, and 39. There was no significant difference in the total score (Table 2 ) therefore, $\mathrm{H} 1$ is largely accepted.

Next, to examine whether people's attitudes towards someone newly diagnosed with dementia and someone living with dementia for a long time would be different $(\mathrm{H} 2)$, the summed score of Questions 30-33 and 36-39 were compared. Those questions asked the same questions about attitudes towards either someone newly diagnosed with dementia (Questions 30-33) and someone who has been living with dementia for a long time (Questions 36-39; Table 1) were compared with Wilcoxon signed-rank test. At the pre-MOOC, their attitude scores towards newly diagnosed were significantly higher than towards long-term (a; Table 3), while at post-MOOC, scores for attitudes towards newly diagnosed were significantly lower than attitudes towards long-term (b). H2 was therefore accepted. Additionally, participants' attitude score towards newly diagnosed decreased significantly $\left({ }^{c}\right)$, while their score for attitudes towards long-term increased significantly (d).

Table 3: Comparisons for the attitudes toward newly-diagnosed and long-term dementia between pre- and post-MOOC scores $(n=107)$

\begin{tabular}{lcccc}
\hline & \multicolumn{2}{c}{ Pre-MOOC } & \multicolumn{2}{c}{ Post-MOOC } \\
& $\mathrm{M}$ & SD & M & SD \\
\hline Newly & $13.35^{\text {ac }}$ & 2.04 & $9.89^{\text {bc }}$ & 3.03 \\
Long-term & $10.78^{\text {ad }}$ & 2.12 & $13.41^{\text {bd }}$ & 3.33 \\
\hline
\end{tabular}

Wilcoxon signed-rank test: Superscripts indicate there was a significant difference in the two groups $(p<.001)$.

\section{Kruskal-Wallis H test}

Kruskal-Wallis $\mathrm{H}$ test was conducted to determine if the change in the attitudes towards dementia between pre- and post-MOOC was different between healthcare workers $(n=65)$ and non-healthcare workers $(n=40$; H3). Distributions of all scores including the total score were similar for both of the groups (healthcare workers and non-healthcare workers), as assessed by visual inspection of a boxplot. There was no significant difference in the total score and all questions between the two groups, apart from Question 38 ("Should someone who has been living with dementia for a long time...Continue to drive"): median scores for Question 38 were statistically significantly different between the two groups, $\chi^{2}(1)=4.85, p=.03$. The change among healthcare workers was larger than non-healthcare workers (Table 4). H3 is therefore partially accepted. 
Table 4: Comparing the change of the attitudes towards dementia between healthcare workers and non-healthcare workers

\begin{tabular}{lccccc}
\hline & \multicolumn{4}{l}{ Healthcare workers $(n=65)$} & \multicolumn{4}{l}{ Non-healthcare workers $(n=40)$} \\
Change (pre-post) & $\mathrm{M}$ & $\mathrm{SD}$ & $\mathrm{M}$ & $\mathrm{SD}$ & $\chi^{2}$ \\
\hline Q15 & .45 & 1.44 & .25 & 1.35 & .56 \\
Q17 & 1.94 & 1.13 & 1.93 & 1.10 & .04 \\
Q19 & 1.65 & 1.20 & 1.63 & 1.21 & .02 \\
Q20 & 1.82 & 1.31 & 1.73 & 1.18 & .29 \\
Q22 & .17 & 1.36 & .03 & 1.29 & .48 \\
Q23 & -.11 & 1.13 & -.11 & 1.31 & .03 \\
Q24 & -.25 & 1.43 & -.33 & 1.27 & .03 \\
Q25 & -1.22 & 1.19 & -.88 & 1.09 & 3.45 \\
Q26 & -1.99 & 1.02 & -1.68 & 1.07 & 1.74 \\
Q27 & -2.32 & .88 & -2.03 & 1.07 & 1.54 \\
Q28 & -.63 & 1.44 & -.79 & 1.42 & .22 \\
Q30 & 1.00 & 1.11 & .69 & 1.08 & 1.79 \\
Q31 & 1.82 & 1.21 & 1.75 & 1.18 & .06 \\
Q32 & .90 & 1.10 & .94 & 1.06 & .03 \\
Q33 & 2.56 & 1.16 & 2.65 & 1.19 & .86 \\
Q36 & .98 & 1.14 & .68 & 1.37 & .57 \\
Q37 & -.31 & 1.45 & -.13 & 1.34 & .46 \\
Q38 & $-1.75^{*}$ & 1.15 & -1.25 & 1.10 & 4.85 \\
Q39 & -1.72 & 1.35 & -1.52 & 1.22 & .88 \\
Total & .21 & 8.15 & .94 & 9.14 & .56 \\
\hline Kruskal-Wallis H test: Significant difference in the two groups ${ }^{*} p<.05,{ }^{* *} p<.01,{ }^{* * *} p<.001$ \\
$\chi^{2}=$ Test statistic (obtained H value) & & & &
\end{tabular}

\section{Correlation}

Because the nominal variables were dichotomous (Gender: $0=$ female, $1=$ male; Country: $0=$ international, $1=\mathrm{UK}$; Job: $0=$ non-healthcare, $1=$ healthcare), point-biserial correlations coefficients are reported. Kendall's tau-b were run to determine the relationship between the change in the attitudes towards dementia, their age, gender, nationality, and job (H4; Table 5). There was no relationship between the demographic information and the total change score. Age was related to the change in question 31 ("Should someone newly diagnosed with dementia...Continue to manage their own medication"), their nationality was related to question 36 ("Should someone who has been living with dementia for a long time...Continue to live alone"), and their job was related to question 38 ("Should someone who has been living with dementia for a long time...Continue to drive"). The total change score was related to most of the questions but especially strongly related to question 36, question 33 ("Should someone newly diagnosed with dementia...Have an electronic device fitted so they can be located if they wander") and question 26 ("There is little or no benefit to be gained from telling someone they have dementia"). H4 is therefore partially accepted. 
Table 5: Kendall's tau-b correlations between demographics and the attitudes towards dementia $(n=107)$

\begin{tabular}{llllllllllllllllllllll}
\hline & Total & Q15 & Q17 & Q19 & Q20 & Q22 & Q23 & Q24 & Q25 & Q26 & Q27 & Q28 & Q30 & Q31 & Q32 & Q33 & Q36 & Q37 & Q38 & Q39 \\
\hline Age & -.04 & -.14 & .15 & -.04 & -.003 & .09 & -.01 & -.02 & -.12 & -.12 & .01 & -.08 & -.10 & $.18^{*}$ & .10 & -.11 & -.07 & -.02 & -.13 & .06 \\
Gender & -.07 & -.02 & -.13 & .13 & -.09 & .02 & .07 & .11 & .01 & -.05 & -.06 & .02 & .002 & -.11 & .04 & -.06 & -.09 & $-.17^{*}$ & -.07 & -.04 \\
Country & .10 & .02 & .05 & .07 & -.12 & -.01 & -.12 & -.05 & .16 & .10 & .13 & .06 & .12 & -.01 & -.12 & .11 & $.21^{*}$ & .09 & -.001 & .17 \\
Job & -.06 & .07 & .02 & .01 & .05 & .06 & -.01 & .02 & -.17 & -.12 & -.11 & .04 & .12 & .02 & -.02 & -.08 & .07 & -.06 & $-.20^{*}$ & -.08 \\
Total & - & .02 & $.15^{*}$ & .07 & .12 & .07 & $.31^{* *}$ & $.40^{* *}$ & $.38^{* *}$ & $.43^{* *}$ & $.40^{* *}$ & $.34^{* *}$ & $.20^{* *}$ & $.23^{* *}$ & .04 & $.45^{* *}$ & $.53^{* *}$ & $.40^{* *}$ & $.23^{* *}$ & $.40^{* *}$ \\
\hline
\end{tabular}

* Correlation is significant at the 0.05 level (2-tailed)

** Correlation is significant at the 0.01 level (2-tailed)

\section{Discussion}

This study aimed to ascertain if a MOOC on dementia can be used to make demonstrable changes to attitudes towards dementia, and four hypotheses were developed to test:

- Hypothesis 1: There would be a significant median difference between pre- and postMOOC assessments for the attitudes towards dementia - partially accepted

- Hypothesis 2: There would be a significant median difference in people's attitudes towards someone who has been newly diagnosed with dementia and who has been living with dementia for a long time - accepted

- Hypothesis 3: The change in the attitudes towards dementia between pre- and postMOOC would be different between healthcare and non-healthcare workers - partially accepted

- Hypothesis 4: The change in the attitudes towards dementia between pre- and postMOOC and demographics would be related to each other - partially accepted

We will discuss each finding in turn.

\section{Hypothesis 1: There would be a significant median difference between pre- and post-MOOC assessments for the attitudes towards dementia-partially accepted.}

Overall, there was a positive improvement in attitudes between the pre- and post-MOOC questionnaires although this difference was not significant. The scores for eight questions decreased significantly, indicating positive effects of the MOOC. These eight questions, especially Q15, 17, 19, and 20 are related to respect to people with dementia. This may suggest one strength of this MOOC. Further research is needed to evaluate these effects. The standard deviation increased in the post-MOOC questionnaire, demonstrating an increased variance in the answers to the questions; this implies participants did have changes in attitudes however these may have changed in either direction. Future research should explore how these differences were made in participants' understanding, in order to provide more standardises effects of MOOCs.

Interestingly, the scores for six questions increased from the pre-MOOC to post-MOOC. For example, Question 26 ("There is little or no benefit to be gained from telling someone they have dementia") showed an increased agreement; more participants thought there was little or no benefit in telling someone they had dementia. This is contrary to one of the founding bases of the course: that information sharing, discussion, and dialogue are important tenets of care. However, this change may be attributable to a reduction in valuing the label of dementia. Those questions need further exploration, in order to understand the experience of the participants and the efficacy of the MOOC. 


\section{Hypothesis 2: There would be a significant median difference in people's attitudes towards dementia between someone who has been diagnosed newly and who has been living with it for a long time - accepted.}

Participants demonstrated a much larger change when asked aspects about newly diagnosed dementia when compared with the same questions asked about someone who has been diagnosed for a long time (driving, independence, electronic tag, managing medication, living alone) which indicates that participants had a greater change in attitudes towards someone newly diagnosed with dementia. This, again, may relate to the label of 'dementia' and the stigma associated with it: after the course, participants were able to more clearly distinguish between the stages of dementia and understand that those with a new diagnosis should maintain as much independence as possible.

\section{Hypothesis 3: The change in the attitudes towards dementia between pre- and post- MOOC would be different between healthcare and non-healthcare workers - partially accepted}

The change in attitudes towards dementia between the pre- and post-MOOC questionnaires among healthcare workers $(\mathrm{M}=.21, \mathrm{SD}=8.15)$ was smaller than among non-healthcare workers $(\mathrm{M}=.94, \mathrm{SD}=9.14)$, but the differences between these groups were not statistically significant $(\mathrm{F}(1,103)=.18, \mathrm{p}=.67)$. The healthcare worker group consisted of a large variation in people employed in the health and social care sector including registered nurses, doctors, physiotherapists, care workers, and social workers. This smaller change in the attitudes of healthcare workers was expected: a possible reason for this is that they are highly likely to have received training on dementia in their foundational pre-qualifying training programmes and continually since qualifying and working in their sector. Most healthcare professionals are required to undertake at least annual update training which often includes training on dementia. An alternative possible explanation for this is also that healthcare professionals can become desensitised to human need as part of their professional socialisation when they enter their profession (Greenwood, 1993). The one question where the change among healthcare workers $(\mathrm{M}=-1.75, \mathrm{SD}=1.15)$ was greater than non-healthcare workers $(\mathrm{M}=-1.25, \mathrm{SD}=1.10), \mathrm{F}(1$, $103)=4.94, \mathrm{p}=.03$ ) was question 38 ("Should someone who has been living with dementia for a long time continue to drive"). It is not clear why there was a change in this specific question.

\section{Hypothesis 4: The change in the attitudes towards dementia between pre- and post- MOOC and demographics would be related to each other-partially accepted.}

Generally as the age of participants increased, their attitudes changed more. This was particularly demonstrable in question 31 ("Should someone newly diagnosed with dementia...Continue to manage their own medication"). This change may be more in older participants as they may be comparing themselves and their own lives to those of people living with dementia; they may have more worries or pre-conceptions about dementia which change over the course.

Participants from the United Kingdom were less likely to agree with the questions asked about independence (in particular question 33, "Should someone newly diagnosed with dementia...Have an electronic device fitted so they can be located if they wander", and 36 "Should someone who has been living with dementia for a long time continue to live alone). This is interesting because the United Kingdom sits highly on the individualistic scale: people in both the UK and Australia value independence and autonomy (Kotera, Adhikari, \& Van Gordon, 2017) and this may be why there was more growth and change in question 36 ("Should someone who has been living with dementia for a long time...Continue to live alone") and question 39 ("Should someone who has been living with dementia for a long time...Have an electronic 
device fitted so they can be located if they wander") among UK-based participants. Question 36 had a high correlation with overall attitude; changes in this score would make changes to the overall score.

Most questions showed a relationship with the overall change, with question 36 ("Should someone who has been living with dementia for a long time continue to live alone") demonstrating the highest correlation with change overall $(r=.53)$. The correlation was so high that answering this question alone would be similar to measuring the rest of the question set: this question is, therefore, a litmus indicator for assessing attitudes towards dementia.

\section{Limitations}

This study has several limitations. The questionnaire used, although implemented on a large scale across Northern Ireland, did not undergo validity testing and therefore the degree of validity or reliability is not known. There was a comparatively small sample size; it is estimated a sample size of over 800 would be required to have high power, however, this population was not available in this study.

This programme lasted six weeks and during this time participants may have been exposed to other events or experiences which could have affected their responses; the only way to eradicate this would be to conduct a shorter programme where participants were detained with no contact with the outside world, however, this is not ethical. The timing of the programme was also important; this programme was delivered in the May of each year; certain periods of the year may have a positive or negative influence on attitudes, for example, Christmas or birthdays and these confounding factors are not accounted for.

Although the whole group was included in the analysis, we did not examine individual participant engagement. It is possible that some learners who engaged more with the course may have varying extents of changes in attitude, or no change in attitude. Participants who completed the survey were generally highly active in the MOOC also.

Some of the scales were reversed so that change went in one direction and was more comparable with other questions. However, this required us to make assumptions about the questions and data, and the way we expected or hoped answers would change. It is possible our interpretation of the questions was not as the original authors intended, although the original question set was designed to determine attitude at one particular time, rather than how attitudes change over time.

This study has assessed attitudes which are difficult to understand and measure due to their individuality, and involvement of feelings and cognition (Myers 2013) which are often difficult to determine using a Likert scale. Unfortunately, this limits the transferability of these findings, however, analysis has remained meaningful as the same participants were in both pre- and postMOOC groups, therefore, the same level of unreliability would be seen in both groups.

\section{Conclusion}

This study has considered the efficacy of a MOOC on dementia as an intervention to change attitudes towards dementia. Our data suggest this MOOC on dementia was more effective in changing the attitudes of non-healthcare workers, older people, and UK-based participants. We suggest that change interventions keep independence, autonomy, and control at the centre of their content because providing awareness training about this particular aspect could change the overall attitudes of dementia. Future areas for investigation therefore include modifications to the MOOC to make independence, autonomy and control more prominent. This study could then be repeated to determine if the size of effect is greater and/or clearer. 
This type of change intervention may be applicable to other health conditions requiring attitudinal change including diabetes, obesity, depression, heart disease, cancer, stroke, alcoholism, and smoking. MOOCs could be employed as public health interventions with potential large-scale impacts on society, however, the size and nature of this impact would require deep and detailed investigation. Our findings may be applicable to other MOOCs, however, it is not possible to determine if MOOCs as a methodology is the change agent alone therefore studies with greater control and randomisation are recommended to determine the effects of MOOCs as an intervention.

\section{Recommendations}

This study recommends:

- Further research to determine the effect size of MOOCs used as change interventions;

- Application of MOOCs as a change intervention to other subject areas to determine if there are changes in attitudes in other disciplines and issues;

\section{References}

1. Allport, G. W. (1935). Attitudes. In Murchison C. (Ed.), Handbook of Social Psychology (pp. 798844). Worcester, MA: Clark University Press.

2. Alzheimer's Society (2015). How to Get in Involved. Retrieved from https://www.dementiafriends.org.uk/Webarticle?Page=How-To-GetInvolved\#.Wyaqqtvkjiu

3. Annear, M. J., Eccleston, C. E., McInerney, F. J., Elliott, K. E. J., Toye, C. M., Tranter, B. K., \& Robinson, A. L. (2016). A new standard in dementia knowledge measurement:

Comparative validation of the dementia knowledge assessment scale and the Alzheimer's disease knowledge scale. Journal of the American Geriatrics Society, 64(6), 1329-1334.

4. British Psychological Society (2017). Ethics Guidelines for Internet-Mediated Research. Leicester: British Psychological Society.

5. Brodaty, H., Draper, B., \& Low, L.F. (2003) Nursing Home Staff Attitudes towards Residents With Dementia: Strain And Satisfaction With Work. J Adv Nursing, 44(6), 583-590.

6. De Bellis, A. M., \& Williams, J. (2008). The Cornell Scale for Depression in Dementia in the Context of the Australian Aged Care Funding Instrument: A Literature Review. Contemporary Nurse, 30(1), 20-31.

7. Devine, P. (2015). NI Life and Times Survey - Dementia Resources. Retrieved from https://www.ark.ac.uk/ARK/resources/teaching

8. Dowds, L., Mcparland, P., Devine, P., Gray, A. M., Byrne, J., Gormley, C., \& Robinson, H. G. (2010). Attitudes to and Knowledge of Dementia in Northern Ireland. Retrieved from https://www.ark.ac.uk/ARK/sites/default/files/2018-08/Dementia.pdf

9. Elvish, R., Burrow, S., Cawley, R., Harney, K., Graham, P., Pilling, M., Gregory, J., Roach, P., Fossey, J., \& Keady, J. (2014). "Getting To Know Me": The Development and Evaluation of a Training Programme for Enhancing Skills in the Care of People with Dementia in General Hospital Settings. Aging \& Mental Health, 18(4), 481.

10. Forman, D., \& Pond, D. (2015). Care of the Person with Dementia $\square$ : Interprofessional Practice and Education. Cambridge University Press. 
11. George, D. R., Stuckey, H. L., \& Whitehead, M. M. (2013). An Arts-Based Intervention at a Nursing Home to Improve Medical Students' Attitudes toward Persons with Dementia. Academic Medicine, 837-842.

12. Goldberg, L. R., Bell, E., King, C., O’Mara, C., McInerney, F., Robinson, A., \& Vickers, J. (2015). Relationship between participants' level of education and engagement in their completion of the Understanding Dementia Massive Open Online Course. BMC medical education, 15(1), 60 .

13. Greenwood, J. (1993). The Apparent Desensitization of Student Nurses During their Professional Socialization: A Cognitive Perspective. J Adv Nurs, 18(9), 1471-9.

14. Grigsby, T. J., Unger, J. B., Molina, G. B., \& Baron, M. (2017). Evaluation of an Audio-Visual Novela to Improve Beliefs, Attitudes and Knowledge toward Dementia: A Mixed-Methods Approach. Clinical Gerontologist, 40(2), 130-138.

15. Harris Interactive (2011). What America Thinks Metlife Foundation Alzheimer's Survey.

16. Hoaglin, D., \& Iglewicz, B. (1987). Fine-Tuning Some Resistant Rules for Outlier Labeling. Journal of the American Statistical Association, 82(400), 1147-1149.

17. Kaminski, J. (2011). Theory Applied to Informatics - Lewin's Change Theory. Canadian Journal of Nursing Informatics, 6(1).

18. Kane, M., \& Terry, G. (2015). Dementia 2015: Aiming Higher to Transform Lives. Retrieved from

https://www.alzheimers.org.uk/sites/default/files/migrate/downloads/dementia_2015_aimi ng_higher_to_transform_lives.pdf

19. Kitwood, T. M. (1997). Dementia Reconsidered: The Person Comes First. Buckingham: Open University Press.

20. Kotera, Y., Adhikari, P., \& Van Gordon, W. (2017). The Relationship between Work Motivation and Worker Profile in UK Hospitality Workers. International Journal of Education, Psychology and Counseling, 2(6), 231-243.

21. Low, L. F., Fletcher, J., Goodenough, B., Jeon, Y. H., Etherton-Beer, C., Macandrew, M., \& Beattie, E. (2015). A Systematic Review of Interventions to Change Staff Care Practices in Order to Improve Resident Outcomes in Nursing Homes. Plos One, 10(11), E0140711

22. Mehta, N. B., Hull, A. L., Young, J. B., \& Stoller, J. K. (2013). Just imagine: new paradigms for medical education. Academic Medicine, 88(10), 1418-1423.

23. Mitchell, G., Mcgreevy, J., Carlisle, S., Frazer, P., Traynor, M., Lundy, H., Diamond, M., \& Agnelli, J. (2016). Evaluation of Dementia Friends Programme for Undergraduate Nursing Students: Innovative Practice. Dementia, 16(8), 1075-1080.

24. Myers, D. (2013). Social Psychology (11 ${ }^{\text {th }}$ ed.). New York: Mcgraw-Hill.

25. Petronzi, D., \& Hadi, M. (2016). Exploring the Factors Associated with MOOC Engagement, Retention and the Wider Benefits for Learners. European Journal of Open, Distance and E-Learning, 19(2), 112-129. https://doi.org/10.1515/eurodl-2016-0011

26. Pot, A. M., Petrea, I., \& Meerveld, J. (2013). Improving Dementia Care Worldwide Ideas and Advice on Developing and Implementing a National Dementia Plan. London. Retrieved from https://www.alz.co.uk/dementia-plans

27. Prince, M., Bryce, R., \& Ferri, C. (2011). World Alzheimer Report 2011: The Benefits of Early Diagnosis and Intervention. London. Retrieved from https://www.alz.co.uk/research/world-report-2011 
28. Rawlings, D., Tieman, J. J., Sanderson, C., Parker, D., \& Miller-Lewis, L. (2017). Never say die: death euphemisms, misunderstandings and their implications for practice. International journal of palliative nursing, 23(7), 324-330.

29. Robertshaw, D., \& Cross, A. (2016). "MOOC" as a Platform for Social Learning, Research and Social Change in Dementia. Proceedings of the European Stakeholder Summit on Experiences and Best Practices in and Around MOOCs (Emoocs 2016).

30. Robertshaw, D., \& Cross, A. (2017). Experiences of integrated care for dementia from family and carer perspectives: a framework analysis of massive open online course discussion board posts. Dementia.

31. Robertshaw, D., \& Cross, A. (2018). Roles and responsibilities in integrated care for dementia. Journal of Integrated Care, 27(2), 131-140. https://doi.org/10.1108/JICA-05-20180037

32. Rodriguez, C. O. (2012). MOOCs and the AI-Stanford like Courses: Two Successful and Distinct Course Formats for Massive Open Online Courses. European Journal of Open, Distance and E-Learning, 2012(II). Retrieved from http:/ / www.eurodl.org/index.php?p $=$ archives\&year $=2012 \&$ halfyear $=2 \&$ article $=516$

33. Scerri, A., \& Scerri, C. (2013). Nursing Students' Knowledge and Attitudes towards Dementia - A Questionnaire Survey. Nurse Education Today, 33(9), 962-8.

34. Tan, Z. S., Damron-Rodriguez, J., Cadogan, M., Gans, D., Price, R. M., Merkin, S. S., Jennings, L., Schickedanz, H., Shimomura, S., Osterweil, D., \& Chodosh, J. (2017). TeamBased Interprofessional Competency Training for Dementia Screening and Management. Journal of the American Geriatrics Society, 65(1), 207.

35. Tukey, J. (1962). The Future of Data Analysis. The Annals of Mathematical Statistics, 33(1), 1-67.

36. World Health Organisation (2012). Dementia: A Public Health Priority. Geneva: WHO.

37. World Health Organization and Alzheimer's Disease International (2012). Dementia: A Public Health Priority. Geneva: World Health Organization.

\section{Acknowledgments}

The authors gratefully acknowledge the support and encouragement provided during the preparation of this paper from Professor Kath Mitchell, Professor Dawn Forman, Professor Chris Brannigan, and Professor David Sheffield.

\section{Declaration of conflicting interests}

The authors declare no potential conflicts of interest with respect to the research, authorship, and/or publication of this article.

\section{Funding}

The authors received no financial support for the research, authorship, and/or publication of this article.

\section{Ethical statement}

Ethical approval was gained from the University of Derby Online Learning's Ethics Committee and conformed to the British Psychological Society's requirements for internet-mediated research (British Psychological Society, 2017). 


\section{Data access statement}

Data can be accessed by contacting the corresponding author or by accessing the University of Derby's Online Research Archive. 